\title{
Student Perceptions of the "Best" Feedback Practices: An Evaluation of Student-Led Teaching Award Nominations at a Higher Education Institution
}

\section{ABSTRACT}

There is great emphasis in contemporary higher education to address the seemingly consistent issue of what students perceive to be good assessment feedback practice. Improving this aspect of the student experience continues to elude higher education institutions, as reflected in the nationally lower than average scores in the United Kingdom's annual National Student Survey questions on prompt feedback, which makes this a timely area for further investigation and discussion. To investigate student perceptions of feedback, this article examines the qualitative data from three years of student-led teaching awards nominations at the University of Winchester for the category "Best Lecturer for Constructive and Efficient Feedback." From this study, new revelations with regard to the student perception of the "best" lecturers' feedback practices have come to light, including terminology, language, and emphasis on email turnaround, rather than the actual format of the feedback itself (such as handwritten, audio, e-submission). Key findings include that students focus on the quality of the linguistic elements of feedback rather than the mode of delivery. The study also finds that students are often perceiving feedback in a literal sense, with many staff nominated based on their informal email responses rather than the formal assignment feedback often attributed to this question in the National Student Survey. In order to tease out the repetitive emerging themes for which practices students are perceiving to be "good" feedback, this article outlines the findings of this study, including the methodology and nomination process of the student-led teaching awards at the University of Winchester.

\section{KEYWORDS}

assessment, feedback, student engagement, student-led teaching awards

\section{INTRODUCTION}

The United Kingdom's higher education system has gone through significant changes during the last decade, including increased student numbers, increased student involvement in all aspects of higher education, changes to the student loan structures, an ever diversifying student body, and an increased emphasis on student employability (Lea, 2015, p. 5). The course of consumerism is a powerful structural factor on the scholarship of teaching and learning in higher education today (Levy, Little, \& Whelan, 2011, p. 2), with emphasis on a students as consumer model prominent within Western postsecondary education (Bunce, Baird, \& Jones, 2017) and transactional outcomes such as graduate employability programmes (Lackner \& Martini, 2017). An additional pressure on UK higher education 
institutions is the external evaluation conducted annually with third-year students in the National Student Survey, which asks final-year undergraduate students 27 (previously 23) questions on how satisfied they were with several aspects of their higher education experience (National Student Survey, 2017). These results lead to university rankings in national leagues tables, along with other sector measurables such as the survey counting towards 25 percent of the new Teaching Excellence and Student Outcomes Framework (Ingham, 2016; National Student Survey, 2017; Teaching Excellence and Student Outcomes Framework, 2019). The questions in the National Student Survey on assessment and feedback have notably been the biggest sources of dissatisfaction since the survey was launched, with UK national satisfaction scores 73 percent satisfied, compared to 84 percent overall satisfaction (National Student Survey, 2017). This causes higher education institutions across the sector to dwell on such questions as how to offer satisfactory, or preferably excellent, feedback practices to better student satisfaction on this question (National Union of Students, 2008; Williams, 2014).

Assessment has been understood to be the key driver of students' learning in higher education, yet feedback practices still require enhancement (Gillett \& Hammond, 2009; Harland, McLean, Wass, Miller, \& Sim, 2015; Jessop \& Maleckar, 2016). The feedback puzzle has created a vast discourse within the scholarship of teaching and learning and at higher education institutions, with several different research discussions and policy decisions conducted to seek to enhance this aspect of the student experience (Williams, 2014). Beaumont, O'Doherty, and Shannon (2011, p. 671) state that students perceived quality feedback as part of a dialogue process rather than an event and outline their dialogue feedback cycle, with pre- and in-task feedback as more effective than summative feedback. They also state that students experience a radically different culture of feedback at higher education compared to school and further education (Beaumont et al., 2011, p. 671). Bennett and Kane (2014, p. 135) suggest that the engaged student perception and interpretations of the meanings of some of the National Student Survey items relating to "the teaching on my course" and to "assessment and feedback" will differ from those of their nonengaged colleagues. This pedagogical issue and area of inquiry within the scholarship of teaching and learning is under particular pressure in UK higher education. Solutions often suggested are moves toward online feedback for greater clarity and engagement, three-week turnarounds to meet student expectations (Debuse \& Lawley, 2016), and enriched feedback experiences from formative, personal, and feed-forward methods following assessments as part of more programmatic assessment practices as suggested by the process offered by the TESTA ("transforming the experience of students through assessment") project: a process that collects evidence about programme assessment patterns, providing a student-centred yet collegiate approach to enhancing student learning, based on assessment principles (Jessop, El Hakim, \& Gibbs, 2014).

Boud and Molloy (2013) speak of the importance of the "feedback loop," or feedback as "gifts," as important framing for feedback as an ongoing process rather than a one-off product (Askew \& Lodge, 2000; Winstone, Nash, Rowntree, \& Parker, 2017) to better scaffold students' learning and increase engagement with feedback. Nicol (2010) emphasizes that instructors need to take a different perspective to tackle dissatisfaction with feedback, blaming massified higher education for squeezing out dialogue, creating a one-way communication burden for students and staff alike. Nicol also argues that feedback should move away from narrowly focusing on performing a pragmatic need to ensuring that the instructors' comments are understandable, selective, specific, contextualized, nonjudgmental, and, of course, timely (2010, p. 513). Ferguson (2011, p. 60) agrees, concluding in his research that students 
seek timely and personalised feedback that has a certain amount of positivity to inspire confidence, acknowledges students' successes, and gives recommendations for future improvements. Ferguson's research also outlines that students welcome online feedback and sometimes found face-to-face feedback in a lecturer's office intimidating (2011, p. 60). These studies are taken into account in the discussion that follows.

\section{STUDENT-LED TEACHING AWARDS}

At the same time as these changes in UK higher education, there has been an aligned emphasis on student engagement, which has largely been embraced by the sector, as a means of enhancing the student experience through engaging students in new places as students as partners in their learning communities (Bryson, 2015; El Hakim, 2017; Lowe \& Dunne, 2017; Quality Assurance Agency, 2012; GuildHE, 2015). As part of this growth of activity, many UK higher education institutions have adopted student-led teaching awards that offer positive feedback to faculty and professional service staff. At University of Winchester, instituting a student-led teaching award was a project borne from the Winchester Student Union and the University of Winchester's shared agenda to expand student feedback on best practice and to enhance the student experience (Lowe, Shaw, Sims, King, \& Paddison, 2017). Feeding into wider institutional strategy, the awards offer an opportunity to explore the unique perceptions from students that help to identify good practice and make a positive influence on learning (Swain, 2012). They provide students with a platform to anonymously nominate any staff for excellence in a host of categories, which can support staff professional development and boost morale (Arthur, 2009). To widen impact, every member of staff who has been nominated for an award is notified of the nomination. Students nominate in such categories as "Inspirational Lecturer of the Year" and "Best Use of Resources." A student committee organises the awards, discussing the nomination process, organising an annual ceremony, and selecting winners based on the qualitative submissions.

As with many colleges and universities, students at Winchester are provided with platforms to engage in representation and democracy, volunteering, researching and creating change (Shaw \& Lowe, 2017). However none previously gave students the ability to solely praise and commend staff for their work and support. The key aspect of these teaching awards is the commitment to being student led, which includes determining the award categories and the winners and coordinating the event. The committee includes the Student Union vice president and the education and student engagement assistant as co-chairs. The other members of the committee are students from across the institution who submit written applications for the position. To ensure more students know about the awards, a campaign of posters, merchandise, and class talks are planned. The campaign has grown each year to include more exciting ways to promote the student-led teaching awards and encourage more students to provide feedback about their educational experience. Laced with positivity and praise, by providing students with a platform to give thanks and encouragement to staff, the student-led teaching awards bridge the gap between staff and students in a way that was previously untapped. The nominations for one category in particular, "Best Lecturer for Constructive and Efficient Feedback," is discussed below. Our hope is that this discussion will isolate student perspectives of feedback and offer an additional new source for data surrounding the complex feedback issue in UK higher education revealed by the results of the National Student Survey. 
Example nominations for this category include the following:

- " $\mathrm{X}$ is concise and constructive with feedback thus helping lots with future work. he also sticks well to deadlines."

- "X always provides constructive feedback, delivers work in a timely manner and makes time to go through feedback on a one-to-one basis should it be required."

- "X gives almost as much feedback on work as the work that has been done itself... She has a passion for teaching and using life examples and supports her students in pushing for the best marks."

We recognise the limitations of the award nominations as data for a study such as this, as we do the contention surrounding student-led teaching awards (Madriaga \& Morley, 2016). The notion of students being given the opportunity to award staff members on their performance throughout the year can be controversial amongst some staff. This is perhaps driven by the "terrors of performativity" (Ball, 2003): staff feel academic freedom and values are being displaced by incentivised effectivity, which dominates over educational honesty, causing a "values schizophrenia" in a performative regime (Ball, 2003). There is a perception that the student-led teaching awards are a popularity contest, won by the most "entertaining" staff member rather than by those conducting educationally purposeful academic work. However, we believe that assessing the feedback question draws least on "performativity" factors alongside valuing the merit of the award nominations in offering a new researchable source of data. We discuss these qualitative nominations below.

\section{METHODOLOGY}

The Winchester Student Union began running the award scheme in the academic year 20132014 , and while the number of student nominations has grown each year, there is still significant room for expansion as students become more aware of their eligibility to nominate. As noted above, in this article, we focus on the number of nominations for category "Best Lecturer for Constructive and Efficient feedback" across the years 2013-2016. The number of nominations is summarised in table 1.

Table 1: Nominations for "Best Lecturer for Constructive and Efficient Feedback"

\begin{tabular}{|l|l|}
\hline ACADEMIC YEAR & NUMBER OF NOMINATIONS FOR CATEGORY \\
\hline $2013-2014$ & 37 \\
\hline $2014-2015$ & 61 \\
\hline $2015-2016$ & 135 \\
\hline
\end{tabular}

Firstly, the research team of two (Lowe and Shaw) anonymized the data removing all names, course titles, and any other information that might make the information identifiable, as the study would be used to report at an internal scholarship of teaching and learning conference on assessment and feedback. The team replaced each of those parts of the data with the letter $X$. The data was then analyzed for common themes to seek out possible tangible best practice or reoccurring themes that students referred to in their nominations across the three years. This was conducted through discussion between 
the two researchers, both of whom work in the area of student engagement and the scholarship of teaching and learning. The themes were derived from the keywords used by the students in the feedback and in relation to the literature and the team's experience working with faculty on the topic of feedback. The largest categories, such as theme 1 ("constructive") and theme 2 ("language used"), are amalgamations of similar keywords that mean similar aspects of feedback. For example, "valuable" and "transferable" feedback are both "constructive" in higher education language. Any disagreements were discussed before a decision was made on a theme allocation. A complete list of themes by year is provided in the appendix. A summary of positive is themes shown in table 2.

Table 2: Summary of positive themes (2013-2016)

\begin{tabular}{|l|l|l|}
\hline REFERENCE NUMBER & THEME & FREQUENCY \\
\hline 1 & constructive (valuable, transferable) & 129 \\
\hline 2 & $\begin{array}{l}\text { language used (sensitive, accessible, clear, } \\
\text { personal) }\end{array}$ & 35 \\
\hline 3 & $\begin{array}{l}\text { above and beyond (outside office hours/ pastoral } \\
\text { care/ quick response to emails) }\end{array}$ & 35 \\
\hline 4 & on time & 29 \\
\hline 5 & detailed & 29 \\
\hline 6 & prior to feedback due date & 12 \\
\hline 7 & concise & 5 \\
\hline 8 & trustworthy (consistent, reliable, fair) & 5 \\
\hline 9 & motivational & 5 \\
\hline 10 & relating to learning outcomes or marking criteria & 2 \\
\hline 11 & engaging & 1 \\
\hline
\end{tabular}

When we were analyzing the data for positive themes, the responses that included modes of feedback practice were recorded, which were originally thought to be the bulk of the data. Furthermore, the team recorded references to negative experiences of feedback, where the nomination would commend a faculty member's practice by referencing that they did not do a practice deemed negative by the student nominating. Both of these are summarized in tables 3 and 4.

Table 3: Summary of practice themes (2013-2016)

\begin{tabular}{|l|l|l|}
\hline REFERENCE NUMBER & THEME & FREQUENCY \\
\hline 12 & face to face & 15 \\
\hline
\end{tabular}




\begin{tabular}{|l|l|l|}
\hline 13 & online submission & 1 \\
\hline 14 & online marking & 2 \\
\hline 15 & online collection & 1 \\
\hline 16 & screencast/visual & 2 \\
\hline 17 & alternative feedback forms & 1 \\
\hline 18 & annotations & 1 \\
\hline 19 & audio feedback & 3 \\
\hline
\end{tabular}

Table 4: Summary of negative comparisons (2013-2016)

\begin{tabular}{|l|l|l|}
\hline REFERENCE NUMBER & THEME & FREQUENCY \\
\hline 20 & "vague" & 1 \\
\hline 21 & illegible format & 2 \\
\hline 22 & "biased" & 1 \\
\hline 23 & unexplained crosses on work & 1 \\
\hline 24 & "ripping essays apart" & 1 \\
\hline 25 & "never leaves me feeling angry or upset" & 1 \\
\hline 26 & "rude" & 1 \\
\hline 27 & bulky feedback forms & 1 \\
\hline
\end{tabular}

With these data, we recognize that there are notable limitations prior to further analysis. Firstly, the qualitative data are award nominations and, therefore, largely positive and possibly persuasive. The accuracy of the accounts written by students in the nominations can be questioned, as they had a motive to write the award nomination for the individual lecturer who they wished to see awarded. Ethical approval was not needed as students were notified upon nominating that their nominations would be used to identify and enhance practice in teaching and learning and for the purposes of this study both the students and the staff are not identifiable. However, students were not asked for examples of good practice in feedback: they were asked to nominate members of faculty who they deemed to be deserving of the award for feedback. This could arguably express a further limitation to the data, for even though it is a rich untapped resource for the higher education discourse about feedback, it was gathered for an alternative purpose and so there are limitations for its specific use as identifying good practice. With these limitations in mind, however, we offer that the dataset does provide testament to practice that 
students deemed to be commendable and thus provides a unique window into student's perception of feedback practices.

\section{DISCUSSION}

When we initially embarked on this inquiry project, the expected outcome was thought to be a qualitative bank of nominations outlining good practical aspects of feedback, such as e-feedback, audio feedback, and certain feedback forms, that are often aligned with enhancing feedback practices (Debuse \& Lawley, 2016). References to the mode of delivery were lower than expected, although this could be due to proportionally fewer faculty using modes of feedback delivery other than the standard practice of written feedback. As shown above in tables 2, 3, and 4, the majority of the themes derived from the data are in fact related to more thematic practices in feedback such as being "transferable" and "constructive" or going "above and beyond," rather than to the mode of the feedback, which are far lower in number in table 3, following Ferguson (2011) and Nicol's (2010) studies. Below, we have grouped the analyzed findings, which we discuss in the context of contemporary higher education.

\section{"Constructive (transferable, valuable)" (theme 1)}

Students identified being constructive as the best attribute to feedback; this appeared 78 times in the nominations. This coincides with the themes of feedback being transferable and valuable for future use in students' assessed work (Ferguson, 2011; Jessop et al., 2014; Nicol, 2010). The concept of portability in feedback has shown to be key to the students' conceptualisation of what is "best" for their feedback. Whilst there is strength in the argument that the word constructive in the question has had a direct causal effect on its prominence in frequency in the nominations, the second adjective within the nomination title, efficient, did not emerge as a theme in the data. This does not dismiss the probable causal effect of its frequency; however, it is a consideration. It is clear that the transferability of feedback for future work plays a vital role in what students are understanding to be the best practice for feedback.

\section{"Language used," "concise," "motivational," and "engaging" (themes 2, 7, 9, 11)}

The linguistic elements of feedback also significantly influence student perceptions of what constitutes best feedback. Students often commented on the language used within the feedback as affecting how they engaged with the feedback. Students stated in their nominations that they would like feedback to be concise, personal, sensitive, motivating, and engaging, a finding that almost directly mirrors Nicol's (2010) recommendations of best practice. Students often stated that they are aware that they are sensitive when receiving feedback on their work, so they appreciate the instructor's taking time and consideration in using language as a tool to transfer the feedback in a motivational way. That "language used" appeared joint second in the frequency of themes highlights how language can significantly affect the way students are engaging with their feedback.

\section{"On time" and "prior to due date" (themes 4 and 6)}

Question 10 of the National Student Survey directly asks about the timeliness of assessment feedback (National Student Survey, 2017; it was question 7 from 2005 to 2016). The data seemed to show that for students, timeliness can be simply having the feedback on time, to actually receiving the feedback prior to the date that is set. Whilst setting the standard for feedback as arriving prior to the due date seems unreasonable considering most academics' workloads, it is interesting to note that "best" 
practice is identified in this study as giving feedback on time. This suggests the benchmark for exceptional feedback practice is set at a level that should be considered standard practice: giving one's students feedback "on time." If it is best practice to give feedback on time (indeed, if it is considered a benchmark standard), perhaps we should be concerned by the fact that when students receive feedback on time, they find it exceptional — even award-worthy—-practice: this suggests that too many instructors are falling below this benchmark.

\section{“Detailed" (theme 5)}

A high proportion of the nominations made reference to "detailed" feedback, suggesting a high volume or level of scrutiny in the feedback. This is possibly an understandable reason to nominate, yet it is less discussed in the literature or policy, which often focuses on turnaround times, usefulness, and means of delivery (Debuse \& Lawley, 2016; Ferguson, 2011). Noting the detailed nature of feedback as an award-worthy attribute suggests the additional time faculty are committing to feedback on the minutiae elements of student work is appreciated and celebrated. Seeing effort in return for the student's own effort offers an interesting perspective on the feedback discourse and certainly links to the identified theme below of "above and beyond." This theme emphasises the student's desire for more than receiving a grade with generic feedback points. "Detailed" suggests a thorough or personal examination of the students' work. The suggestion that students value detailed feedback also suggests, in turn, that students take the time to thoroughly read and use that feedback.

\section{"Above and beyond" (theme 3)}

This theme provided some interesting and possibly concerning attributes. For students, going "above and beyond" meant anything from providing very useful draft feedback for their assignment to responding to emails no matter what hour of day (or night in some instances), the student contacted the instructor. What was particularly key in this theme was that the word feedback was directly related not only to their assignment feedback, but also to feedback to queries on emails. The nominations that contributed to this theme focused quite considerably on the quick responses from instructors to their students' emails. This is perhaps a vital consideration for the National Student Survey questions on feedback as many institutions choose to set deadlines for marking assignments and providing feedback. If this is how the National Student Survey is being interpreted by students — that "timeliness" does not solely relate to feedback on assignments being delivered on time-instructors might also start to consider how "timely" their feedback is to student email queries. As Bennett and Kane (2014) caution, students' understanding of certain words, such as feedback, in higher education settings can be understood differently, thus affecting responses.

\section{"Trustworthy" ("consistent," "reliable," "fair") (theme 8)}

That students commended faculty feedback practices for being "trustworthy," "fair," or "reliable" received five nominations could be argued as a reflection on a pressured higher education system that places emphasis on student outcomes and achievements. Although this is a positive nomination, this theme is concerning as to be commended for giving trustworthy feedback (or marks on assignments) suggests that others are perhaps not. These commendations suggest that those students who nominated for these reasons have found certain faculty member's trustworthiness or reliability as exceptional, which 
indicates a wider issue that others are viewed as falling short of this. Although a commendation, this identifies an issue that could be occurring behind the data and that can be helped through departmental marking calibration workshops and transparency of marks attributed to comprehensive marking criteria.

\section{"Relating to learning outcomes" or "marking criteria" (theme 10)}

Perhaps worryingly for some policy makers who champion aligning feedback to learning outcomes or marking criteria, in only two nominations did students specifically celebrate this practice. As this is a far less frequent theme, this could be reflected upon either positively or negatively. In a positive sense, it may be that colleagues are rarely emphasising the importance of cross referencing the marks awarded to the learning outcomes or marking criteria, which could be a useful step forward for the sector's building the trustworthiness of their marking. However, in a negative sense, it could also be that students are not engaging with the marking criteria at all because they do not value this practice. Finally, in neither a positive nor negative sense, it could be that engaging with the learning outcomes and marking criteria is seen as standard practice by students, which is why it is not referenced in the nominations, as this is expected practice rather than award worthy.

\section{Practical themes (themes 12-19)}

Table 3 provides examples of assessment that students saw to be particularly valuable assets to the feedback experience. Perhaps unsurprisingly, the most frequently cited method of receiving feedback was a face-to-face meeting. This is a practice that is often referred to as the best method of delivering feedback to students, as it opens up a dialogue (Merry, Price, Carless, \& Taras, 2013). There are practical elements to consider here, such as the time needed to deliver this type of feedback to all students. Whilst students recognise this is the best delivery of feedback, this is not the most timeefficient mode of delivery. Other tools such as audio and video were valued by students, as it adds a personal dimension to the feedback students receive. Where written text can be often perceived negatively, hearing the voice of the instructor, and the tone of delivery can affect or change the interpretation of feedback. Students commented in their nominations that the tone of delivery for feedback, both linguistically and audibly, made a considerable difference to their response to the feedback.

\section{Negative themes (themes 20-27)}

Whilst student-led teaching awards are a platform for praise and commending staff, we found occurrences in the data where a student would be praising their nominee by contrasting them to (an always anonymous) experience of bad practice, as is suggested by the finding that students considered timeliness of feedback and fairness to be worthy of note. For example, students would note that an instructor provided constructive feedback, instead of "ripping essays apart." These themes, identified in table 4, are interesting because they reveal some of the negative experiences that led the students to nominate an instructor as an exemplary model for good feedback practices. These themes are shown in Appendix 1 and table 4. In table 4, a student commented on the "bulky feedback forms" that led to a negative experience, which their nominee contrastingly did not use. This is again another example of the word feedback being attributed to "feedback forms" and not assessment feedback. The National Student Survey feedback question is perhaps being interpreted to mean the feedback forms students fill in for 
staff in the form of module evaluations. Although in this article we are mostly interested in the positive attributes of feedback for which students have commended staff, the negative themes provide some interesting insight to the students' perceptions of experiences that could be deemed to be "worst," rather than "best," feedback practices.

\section{CONCLUSION}

This article adds to the discourse surrounding student satisfaction and the student perspective of the best feedback practices. While our small-scale study at one higher education institution may not be generalisable, it nevertheless sheds an interesting light on the perceptions students have on assessment and feedback practices. In summary, we offer four take-away messages about our findings.

First, there was significant response and focus on the quality of the linguistic elements of feedback, such as transferable feedback, the types of language used, and the detailed personalisation of the feedback.

Secondly, the mode of delivery of the feedback did not figure as much as the researchers expected, with few references to feedback modes (such as audio or written). That said, however, students valued the legibility of written feedback which suggests that typed feedback might be advised.

Third, it was the trustworthiness of the feedback itself that mattered to the students, as did the timeliness. The fact that such practice was deemed award-worthy suggests that the benchmark for standard practice is quite low.

Fourth, students consider a wider range of communication from their instructors to be providing feedback, not just the formal or summative feedback on assignments: they include email responses (formative and informal feedback) and feedback forms. Perhaps caution should be advised to faculty and senior administrators who often focus entirely on assignment feedback return timeframes following submission. Our study shows that students are interpreting feedback in a broader and perhaps more literal sense than do faculty and administrators, who consider it only as part of the assessment process, and it suggests that students may be thinking of informal feedback practice on emails as well as assessment feedback when completing the National Student Survey.

Tom Lowe is Centre for Student Engagement Manager and Acting Head of Careers at the University of Winchester (UK). He was previously Vice President, Education at Winchester Student Union, where he coordinated the Student-Led Teaching Awards in 2014 and 2015.

Cassie Shaw is Learning and Teaching Enhancement Officer and Lecturer at the University of Winchester (UK). She was previously Student Engagement Assistant at Winchester Student Union, where she coordinated the Student-Led Teaching Awards in 2016.

\section{REFERENCES}

Arthur, L. (2009). From performativity to professionalism: Lecturers responses to student feedback. Teaching in Higher Education, 14(4), 441-454. https://doi.org/10.1080/13562510903050228.

Askew, S., \& Lodge, C. (2000). Gifts, ping-pong and loops: Linking feedback and learning. In S. Askew (Ed.), Feedback for learning (pp. 1-17) London: RoutledgeFalmer.

Ball, S. J. (2003). The teacher's soul and the terrors of performativity. Journal of Education Policy, 18(2), 215-228. https://doi.org/10.1080/0268093022000043065.

Beaumont, C., O'Doherty, M., \& Shannon, L. (2011). Reconceptualising assessment feedback: a key to improving student learning? Studies in Higher Education, 36(6), 671-687. https://doi.org/10.1080/03075071003731135. 
Bennett, R., \& Kane, S. (2014). Students' interpretations of the meanings of questionnaire items in the National Student Survey. Quality in Higher Education, 20(2), 129-164. https://doi.org/10.1080/13538322.2014.924786.

Boud, D., \& Molloy, E. (2013). Rethinking models of feedback for learning: The challenge of design. Assessment \& Evaluation in Higher Education, 38(6), 698-712. https://doi.org/10.1080/02602938.2012.691462.

Bovill, C. (2017). Maintaining criticality: Attempts to stop an unacceptable proportion of students from feeling alienated. The Journal of Educational Innovation, Partnership and Change, 3(1), 14-17. http://dx.doi.org/10.21100/jeipc.v3i1.681.

Bryson, C. (2015). Researching, advancing and inspiring student engagement (RAISE). In J. Lea (Ed.), Enhancing learning and teaching in higher education: Engaging with the dimensions of practice (pp. 163-165). Maidenhead: Open University Press.

Bunce, L., Baird, A., \& Jones, S.E. (2017). The student-as-consumer approach in higher education and its effects on academic performance. Studies in Higher Education, 42(11), 1958-1978. https://doi.org/10.1080/03075079.2015.1127908.

Debuse, J.C.W., \& Lawley, M. (2016). Benefits and drawbacks of computer-based assessment and feedback systems: Student and educator perspectives. British Journal of Educational Technology, 47(2), 294-301. https://doi.org/10.1111/bjet.12232.

El Hakim, Y. (2017). Where next for student engagement? Journal of Educational Innovation, Partnership and Change, 3(1), 90-92. http://dx.doi.org/10.21100/jeipc.v3i1.648.

Ferguson, P. (2011). Student perceptions of quality feedback in teacher education. Assessment \& Evaluation in Higher Education, 36(1), 51-62. https://doi.org/10.1080/02602930903197883.

Gillett, A., \& Hammond, A. (2009). Mapping the maze of assessment: An investigation into practice. Active Learning in Higher Education, 10(2), 120-137. https://doi.org/10.1177/1469787409104786.

GuildHE (2015). Making student engagement a reality: Turning theory into practice. Retrieved from https://www.guildhe.ac.uk/wp-content/uploads/2015/11/6472-Guild-HE-Student-Engagement-Report36pp.pdf.

Harland, T., McLean, A., Wass, R., Miller, E., \& Sim, K. N. (2015). An assessment arms race and its fallout: High-stakes grading and the case for slow scholarship. Assessment \& Evaluation in Higher Education, 40(4), 528-541. https://doi.org/10.1080/02602938.2014.931927.

Higher Education Academy. (2018). Student led teaching awards. Retrieved from http://www.studentledteachingawards.org.uk/history-of-the-project/.

Ingham, D. (2016). An answer from research to the Teaching Excellence Framework-student engagement and graduate engagement to evidence legacy. Student Engagement in Higher Education Journal, 1(1), 1-22. Retrieved from https://journals.studentengagement.org.uk/index.php/raise/article/view/377/336.

Jessop, T., El Hakim, Y., \& Gibbs, G. (2014). TESTA in 2014: A way of thinking about assessment and feedback. Educational Developments, 15(2), 21-24. Retrieved from https://www.seda.ac.uk/resources/files/publications 187 Ed\%20Devs\%2015.2\%20FINAL.pdf.

Jessop, T., \& Maleckar, B. (2016). The influence of disciplinary assessment patterns on student learning: A comparative study. Studies in Higher Education, 41(4), 696-711. https://doi.org/10.1080/03075079.2014.943170.

Lackner, C., \& Martini, T. (2017). Helping university students succeed at employment interviews: The role of selfreflection in e-portfolios. Teaching \& Learning Inquiry, 5(2), 3-15. https://doi.org/10.20343/teachlearninqu.5.2.2.

Lea, J. (Ed.) (2015). Enhancing learning and teaching in higher education: Engaging with the dimensions of practice. Maidenhead: Open University Press.

Levy, P., Little, S., \& Whelan, N. (2011). Perspectives on staff-student partnerships in learning, research, and educational enhancement. In S. Little (Ed), Staff-student partnerships in higher education (pp. 1-15). London: Continuum.

Lowe, T., \& Dunne, E. (2017). Setting the scene for the REACT programme: Aims, challenges and the way ahead. Journal of Educational Innovation, Partnership and Change, 3(1), 24-39. http://dx.doi.org/10.21100/jeipc.v3i1.678. 
Lowe, T., Shaw, C., Sims, S., King, S., \& Paddison, A. (2017). The development of contemporary student engagement practices at the University of Winchester. International Journal of Students as Partners, 1(1). https://doi.org/10.15173/ijsap.v1i1.3082.

Madriaga, M., \& Morley, K. (2016). Awarding teaching excellence: "What is it supposed to achieve?" Teaching in Higher Education, 21(2), 166-174. https://doi.org/10.1080/13562517.2015.1136277.

Merry, S., Price, M., Carless, D., \& Taras, M. (2013). Conclusion and reflections. In S. Merry (Ed.) Reconceptualising feedback in higher education: Developing dialogue with students. (pp. 204-210). London: Routledge.

National Student Survey. (2017). About the NSS. Retrieved from http://www.thestudentsurvey.com/about.php.

National Union of Students. (2008). NUS student experience report. Retrieved from http://www.nus.org.uk/PageFiles/4017/NUS StudentExperienceReport.pdf

Nicol, D. (2010). From monologue to dialogue: Improving written feedback processes in mass higher education. Assessment \& Evaluation in Higher Education, 35(5), 501-517. https://doi.org/10.1080/02602931003786559.

Quality Assurance Agency. (2012). UK quality code for higher education. Part B: Assuring and enhancing academic quality. Chapter B5: Student engagement. Retrieved from https://www.qaa.ac.uk/docs/qaa/quality-code/chapter-b5 -student engagement.pdf?sfvrsn=cd01f781 8 .

Shaw, C., \& Lowe, T. (2017) The student participation map: A tool to map student participations, engagements, opportunities and extra-curricular activities across a higher education institution.' Dialogue: Journal of Learning and Teaching, 1, 45-50. ISSN 23399-701X. Retrieved from: https://issuu.com/solentuniversity/docs/dialogue 2016-17

Swain, J. (2012) Scoping the landscape: An audit of student led teaching awards project provision across the UK. London: Higher Education Academy and National Union of Students. Retrieved from http://www.studentledteachingawards.org.uk/wp-content/uploads/2014/03/SLTA-landscapereport.pdf.

Teaching Excellence and Student Outcomes Framework (2019). Retrieved from https://www.officeforstudents.org.uk/advice-and-guidance/teaching/what-is-the-tef/.

Williams, J. (2014). Student feedback on the experience of higher education: A significant component of institutional research data. In M.E. Menon, D. G. Terkla, \& P. Gibbs (Eds.), Using data to improve higher education: research, policy and practice (pp. 67-80). Rotterdam: Sense.

Winstone, N.E., Nash, R.A., Rowntree, J., \& Parker, M. (2017). "It'd be useful, but I wouldn't use it": Barriers to university students' feedback seeking and recipience. Studies in Higher Education, 42(11), 2026-2041. https://doi.org/10.1080/03075079.2015.1130032.

\section{APPENDIX: STUDENT-LED TEACHING AWARDS DATE, TABLE OF THEMES BY YEAR}

Table of themes: 2013-2014 (37 nominations)

\begin{tabular}{|l|l|}
\hline THEME & FREQUENCY \\
\hline quick email correspondence & 6 \\
\hline constructive (valuable, transferable) & 22 \\
\hline Fair & 1 \\
\hline concise & 1 \\
\hline trustworthy & 1 \\
\hline on time & 3 \\
\hline
\end{tabular}




\begin{tabular}{|l|l|} 
quick to solve issues & 1 \\
\hline above and beyond (outside office hours) & 9 \\
\hline positive personal attributes/characteristics & 7 \\
\hline face to face & 3 \\
\hline detailed & 5 \\
\hline relating to learning outcomes/marking criteria & 1 \\
\hline structured & 1 \\
\hline prior to feedback due date & 2 \\
\hline clear & 1 \\
\hline accessible language & 1 \\
\hline sensitive language & 1 \\
\hline NEGATIVE THEMES & 1 \\
\hline "vague" & 1 \\
\hline "scruffy handwriting" & 1 \\
\hline "not biased" & \\
\hline
\end{tabular}

Table of themes: 2014-2015 (61 nominations)

\begin{tabular}{|l|l|}
\hline THEME & FREQUENCY \\
\hline quick email correspondence & 4 \\
\hline constructive (valuable, transferable) & 31 \\
\hline concise & 1 \\
\hline on time & 11 \\
\hline above and beyond (outside office hours) & 5 \\
\hline positive personal attributes/characteristics in feedback & 2 \\
\hline face to face & 3 \\
\hline detailed & 11 \\
\hline
\end{tabular}




\begin{tabular}{|l|l|} 
relating to learning outcomes/marking criteria & 1 \\
\hline prior to feedback due date & 6 \\
\hline clear & 5 \\
\hline sensitive language & 1 \\
\hline online submission & 1 \\
\hline online marking & 2 \\
\hline online collection & 1 \\
\hline screencast & 1 \\
\hline alternative feedback forms & 1 \\
\hline motivational & 1 \\
\hline NEGATIVE THEMES & 1 \\
\hline illegible format & 1 \\
\hline unexplained crosses on work & 1 \\
\hline "ripping essays apart" & 1 \\
\hline "Never leaves me feeling angry or upset" & 1 \\
\hline bulky feedback forms & 1 \\
\hline
\end{tabular}

Table of themes: 2015-2016 (135 nominations)

\begin{tabular}{|l|l|}
\hline THEMES & FREQUENCY \\
\hline quick email correspondence & 6 \\
\hline constructive (valuable, transferable) & 74 \\
\hline fair & 1 \\
\hline concise & 3 \\
\hline trustworthy (fair) & 2 \\
\hline on time & 15 \\
\hline above and beyond (outside office hours, pastoral care) & 4 \\
\hline positive personal attributes/characteristics in feedback & 5 \\
\hline
\end{tabular}




\begin{tabular}{|l|l|} 
Face to Face & 7 \\
\hline detailed & 11 \\
\hline prior to feedback due date & 4 \\
\hline clear & 10 \\
\hline accessible language & 1 \\
\hline sensitive language & 1 \\
\hline screencast/visual & 1 \\
\hline motivational & 4 \\
\hline quantity & 1 \\
\hline annotations & 1 \\
\hline consistency in marking & 1 \\
\hline critical & 2 \\
\hline audio feedback & 3 \\
\hline engaging & 1 \\
\hline
\end{tabular}

Copyright for the content of articles published in Teaching \& Learning Inquiry resides with the authors,
and copyright for the publication layout resides with the journal. These copyright holders have agreed
that this article should be available on open access under a Creative Commons Attribution License 4.0 International
(https://creativecommons.org/licenses/by/4.0). The only constraint on reproduction and distribution, and the only role for
copyright in this domain, should be to give authors control over the integrity of their work and the right to be properly
acknowledged and cited, and to cite Teaching \& Learning Inquiry as the original place of publication. Readers are free to
share these materials-as long as appropriate credit is given, a link to the license is provided, and any changes are
indicated.

